\title{
Oral Health
}

\section{Evidence-based recommendation on toothpaste use ${ }^{*}$}

Jaime Aparecido Cury Livia Maria Andaló Tenuta

Piracicaba Dental School, University of Campinas - UNICAMP, Piracicaba, SP, Brazil.

* Paper presented at the "Equity, Social Inclusion and Oral Health Promotion: Major Challenges" International Symposium, Held at the $18^{\text {th }}$ Congress of the Brazilian Association for Oral Health Promotion (Associação Brasileira de Odontologia de Promoção de Saúde - ABOPREV), April 2013, Bauru, SP, Brazil.

Declaration of Interests: The authors certify that they have no commercial or associative interest that represents a conflict of interest in connection with the manuscript.

Corresponding Author:

Jaime Aparecido Cury

E-mail: jcury@fop.unicamp.br

http://dx.doi.org/10.1590/S1806-83242014.50000001 Epub Jan 24, 2014

Submitted: Sep 02, 2013

Accepted for publication: Nov 04, 2013

Last revision: Dec 09, 2013
Abstract: Toothpaste can be used as a vehicle for substances to improve the oral health of individuals and populations. Therefore, it should be recommended based on the best scientific evidence available, and not on the opinion of authorities or specialists. Fluoride is the most important therapeutic substance used in toothpastes, adding to the effect of mechanical toothbrushing on dental caries control. The use of fluoride toothpaste to reduce caries in children and adults is strongly based on evidence, and is dependent on the concentration (minimum of 1000 ppm F) and frequency of fluoride toothpaste use $(2 \times /$ day or higher). The risk of dental fluorosis due to toothpaste ingestion by children has been overestimated, since there is no evidence that: 1) fluoride toothpaste use should be postponed until the age of 3-4 or older, 2) low-fluoride toothpaste avoids fluorosis and 3) fluorosis has a detrimental effect on the quality of life of individuals exposed to fluoridated water and toothpaste. Among other therapeutic substances used in toothpastes, there is evidence that triclosan/copolymer reduce dental biofilm, gingivitis, periodontitis, calculus and halitosis, and that toothpastes containing stannous fluoride reduce biofilm and gingivitis.

Descriptors: Toothpastes; Fluorides; Dental Caries.

\section{Introduction}

Any successful therapeutic agent has to pass the scrutiny of clinicallyproven effects to be widely recommended. In Dentistry, scientific-based clinical practice has been advocated in the last decades as a mandatory approach to any clinical recommendation. ${ }^{1}$ Moreover, for those clinical decisions for which there is no defined scientific-based evidence, dentists should ally their patients needs with their clinical experience to achieve the best possible treatment considering the evidence available. ${ }^{1}$

By choosing the best treatment option for their patients, dentists, as well as oral health councilors, embrace their responsibility as health professionals. Therefore, the scientific-based approach to solving clinical problems offers health professionals a safe way to practice high quality dentistry. Fortunately, where dental caries is concerned, there is a strong level of evidence, based not only on epidemiological data from many countries, such as Brazil, but also from clinical trials, ${ }^{2,3}$ to support water fluoridation and the widespread use of fluoride toothpastes as highly successful protocols for caries control. ${ }^{4,5}$ Nevertheless, the successful history of fluoride use for caries control has been recently threatened by 
general concern over an increase in the prevalence of dental fluorosis, although there is no evidence that fluorosis caused by the use of fluoridated water and toothpaste affects the well-being or the oral healthrelated quality of life of affected individuals. ${ }^{6,7,8,9,10}$

In the present paper, the main scientific-based recommendation for fluoride toothpaste use will be critically discussed, considering the responsibility of health professionals to use the best evidence available to maximize the benefits of its use, while minimizing the potential risks. Also, the recommendations with regard to multiple purpose toothpastes will be briefly addressed.

\section{Chemical composition of fluoride toothpastes}

Toothpastes have been widely used since ancient times as cleaning agents. ${ }^{11}$ But it was only in the last century that effective therapeutics, mainly fluoride, were incorporated into their formula, resulting in significant improvements to the oral health of populations worldwide. ${ }^{12}$ Therefore, more than merely cosmetic products, toothpastes have become essential for oral health maintenance.

Among the components of toothpaste formulations, two deserve further discussion given their important role in the mode of action of toothpastes:

- abrasives and

- therapeutic agents.

Abrasive agents are important for a given toothpaste to be effective as a dental stain and plaque removing agent. In fact, toothbrushing compliance is reduced under the use of an abrasive-free formula, due to the poor cleaning capacity of the toothbrush alone in removing pellicle, resulting in increased tooth staining and rapid dental biofilm regrowth. ${ }^{13}$ However, the abrasive agent has an important role in overall toothpaste performance based on the possible interaction of some abrasives (calcium-based) with fluoride, making the latter insoluble and therefore ineffective. In fact, the first fluoride toothpastes marketed were not able to control caries progres$\operatorname{sion}^{14}$ because they were formulated with abrasives containing calcium and sodium fluoride; since sodium fluoride is highly soluble, the ionic fluoride released reacts with calcium ions from the abrasive system, forming low solubility calcium fluoride salts. Since fluoride has to be free to interact with de- and remineralization processes in order to control caries, ${ }^{15}$ such formulations were unable to show any anticaries effect.

In order to incorporate low-cost, calcium-based abrasives in toothpaste formulations while maintaining their quality, i.e. the anticaries effect of the formulation, a compatible fluoride form was developed: sodium monofluorophosphate salt. This ionizes releasing the monofluorophosphate ion, in which fluoride is covalently bound to the phosphate group and therefore cannot react with calcium ions released from the abrasive system. It is only in the mouth that the monofluorophosphate ion will release ionic fluoride, due to the action of unspecific oral phosphatases. ${ }^{16,17}$ Nevertheless, the longevity of the activity of these toothpaste formulations needs to be assessed over time, because part of the fluoride is released from the monofluorphosphate ion during storage of the toothpaste, reacting with calcium and forming insoluble fluoride. Fortunately, assessments of these toothpastes, widely available in countries like Argentina, ${ }^{18}$ Chile (unpublished data) and Brazil, ${ }^{4,19,20,21}$ have shown that they maintain their anticaries activity for the period of time they would be used by the population.

\section{Fluoride toothpastes, caries control and fluorosis risk}

How fluoride toothpastes control caries and the evidence-based recommendations

It is noteworthy that toothbrushing as an isolated effect, i.e., without the therapeutic effect of fluoride, has only a limited effect on caries control. ${ }^{22,23}$ Although this may seem to be a paradox, given the importance of dental biofilm for caries development and the expected role of its removal in caries control, only a fluoride toothpaste is able to replenish the oral cavity with fluoride and therefore impair caries progression even where toothbrushing is not perfect (which is the site of caries development). Therefore, for complete oral health care, regular toothbrushing with a fluoride toothpaste is essential to control caries. ${ }^{3,22,23,24,25}$ This substantiates the 
strong evidence for the role of fluoride toothpastes in dental caries decline derived from systematic reviews of the scientific literature. ${ }^{3}$

Although the mode of action of fluoride reducing dental demineralization and enhancing remineralization is well understood, ${ }^{15}$ a few words are necessary where the mode of action of fluoride toothpaste is concerned. ${ }^{26}$ Brushing with fluoride toothpaste causes a transient increase in fluoride concentration in saliva, which lasts for a few hours. More importantly, fluoride concentration in the fluid phase of remnants of dental biofilm could be maintained at higher values for longer periods of time, given the reduced clearance in such sites. ${ }^{27,28}$ Therefore, fluoride could act not only to enhance dental remineralization on cleaned surfaces, but also to reduce demineralization on surfaces covered by biofilm remnants.

Given the high fluoride concentration present in toothpastes (1000-1500 ppm F), it is expected that they react with tooth surfaces forming a calcium fluoride-like reservoir that is released in between brushings. Nevertheless, the capacity to form such reservoirs during short-term intraoral exposure to toothpaste is small; moreover, the few reservoirs formed are lost rapidly after toothbrushing. When compared to the anticaries effect of fluoride remaining in biofilm not removed after brushing, the effect of calcium fluoride-like reservoirs on toothpaste efficacy seems irrelevant. ${ }^{29}$

Where fluoride concentration in toothpastes is concerned, a long debate can be observed in the literature regarding the anticaries effect of low-fluoride toothpastes (e.g. 500 ppm F). Originally marketed to overcome potential fluorosis risks due to inadvertent ingestion of toothpaste by young children during toothbrushing, ${ }^{30}$ low-fluoride toothpastes are available in many countries and are even endorsed by some governmental oral health agencies. ${ }^{31}$ However, their anticaries effect has not been confirmed in systematic reviews. ${ }^{25,32}$ In experiments designed to evaluate the anticaries effect of low-fluoride toothpastes under different cariogenic conditions, it was demonstrated that, for caries-active children ${ }^{33}$ or for those subject to a high cariogenic challenge (biofilm accumulation and exposure to sugar 6-8 times/day), ${ }^{28}$ low-fluoride toothpaste is significantly less effective than conventional fluoride toothpaste (1100 ppm F) in controlling caries progression. Considering the data currently available on the anticaries effect of toothpastes with different fluoride concentrations on children and adolescents ${ }^{32}$ or on primary dentition of preschool children, ${ }^{25}$ the only scientific-based recommendation is that a small amount of toothpaste with at least $1000 \mathrm{ppm} \mathrm{F}$ be used, irrespective of child's age.

When root caries is a concern, since dentine is more soluble than enamel, fluoride toothpaste is expected to be less effective in controlling dentin caries than in controlling enamel caries. ${ }^{34}$ Therefore, highfluoride toothpastes (e.g. 5000 ppm F) marketed to control root caries have been shown by clinical trials $^{35}$ to have a higher effectiveness than conventional-concentration toothpastes (1000-1500 ppm F).

Regarding toothbrushing frequency, there is evidence that it is more effective when performed at least twice a day. ${ }^{3}$ Also, there is evidence that toothbrushing directed at high caries risk teeth, such as erupting first permanent molars, is $50 \%$ more effective when performed twice a day than it is when performed once a day or less. ${ }^{36}$

When fluoride toothpaste is used concomitantly with other fluoride modalities aimed at high caries risk patients, the additional effect found in mechanistic studies ${ }^{37}$ or in systematic reviews of the literature $^{38}$ is limited. This may be explained by the similar mode of action of the many fluoride options available, i.e. reducing enamel demineralization and enhancing enamel remineralization. Therefore, there is a limit to the effect that one method can add to another.

\section{Fluoride toothpastes and fluorosis risk: the evidence available}

Where fluorosis is concerned, there is a serious debate on the role of the distinct sources of systemic fluoride in the development of fluorosis, especially when levels of aesthetic concern are considered.

It has been accepted that the widespread use of fluoridated water and fluoride toothpastes is related to the current levels of fluorosis observed in the populations exposed to both. However, the relative 
role of both to fluorosis levels is still not clear. A systematic review of the literature was unable to find strong evidence supporting the hypothesis that the use of fluoride toothpaste by young children is associated with an increased risk of fluorosis. ${ }^{39}$ Furthermore, a recent systematic review showed that the use of a low-F toothpaste increases the caries risk and does not reduce the risk of aesthetically objectionable fluorosis. ${ }^{40}$

It is also noteworthy that the epidemiological data on fluorosis currently available in countries regularly using fluoridated water and toothpastes clearly shows that fluorosis is not a concern from the public health point of view. The overall prevalence of moderate fluorosis in the Brazilian population was shown to be $1.5 \%$, with an insignificant prevalence of severe fluorosis. ${ }^{41}$ Of the $25.2 \%$ of 12 -yearolds presenting any level of fluorosis, the majority $(19.3 \%)$ show questionable and very mild levels. ${ }^{41}$ This data indicates that the discussion on fluorosis risk from toothpastes does not necessarily reflect its epidemiological distribution on a population level.

More importantly, there is considerable evidence $^{42}$ on the effect of the level of dental fluorosis on the oral health-related quality of life of those affected. It has shown that very mild and mild fluorosis-the levels associated with the regular use of conventional methods for caries prevention, such as fluoridated water and toothpaste-are not a concern.

In fact, most of the data on fluoride toothpaste use and risks of fluorosis are based on dose of fluoride ingestion by children and not on the outcome of fluorosis. The role of diet (fluoridated water) and fluoride toothpaste use in the daily dose of fluoride ingestion by young children has been used as a basis for recommendations on fluoride use by young children. However, there is no longitudinal study demonstrating that children exposed to a higher dose when very young develop more severe levels of fluorosis. ${ }^{43,44}$ Many confounding factors may interfere with these results. For example, some toothpaste formulations contain a soluble, bioavailable (absorbable) fluoride concentration that is lower than the total concentration in the formulation. ${ }^{20}$ Since insoluble fluoride is not absorbed, ${ }^{45}$ the fluorosis risk from toothpastes containing $\mathrm{CaCO}_{3}$ may be overestimated by 50\%. ${ }^{46}$ Also, if fluoride toothpaste is ingested up to 15 minutes after meals, absorption is considerably reduced. ${ }^{47}$

Therefore, based on the best available evidence for recommending fluoride toothpaste use considering the balance of its benefits and risks, a conventional fluoride toothpaste (1000-1500 ppm F) should be used by all individuals, irrespective of age, with young children using a small amount (0.1$0.3 \mathrm{~g}){ }^{48}$ For adults, where root caries is a concern, a high-fluoride toothpaste may be an option.

\section{Multi-purpose toothpastes}

Although fluoride is the cornerstone of the anticaries agents in toothpastes, there is more than just fluoride. ${ }^{49} \mathrm{~A}$ number of co-adjuvant anticaries agents have been tested and made available in toothpaste formulations, with evidence of effectiveness. One of the most tested is triclosan. Formulations containing triclosan/copolymer have been shown to significantly reduce gingival inflammation and the progression of gingivitis to periodontitis, calculus and halitosis. ${ }^{50,51}$ Stannous fluoride toothpastes were also shown to have a significant effect on biofilm reduction and gingivitis. ${ }^{52}$

Regarding dentin hypersensitivity, the evidence to support potassium-containing toothpastes is not sound enough. ${ }^{53}$ More recent formulations, such as arginine-based toothpastes, have shown promising results in clinical trials ${ }^{54}$ to be confirmed by systematic reviews of the literature.

The control of calculus formation by toothpastes is based on evidence, especially for formulations containing pyrophosphates, zinc compounds and co-polymers. ${ }^{55}$

\section{Conclusions}

1. The importance of fluoride toothpaste use for caries control is based on dozens of clinical studies, which have shown that there is strong evidence that brushing with a fluoride-containing toothpaste is more effective than brushing with a non-fluoride toothpaste. ${ }^{3}$

2. Although children inadvertently ingest part of the toothpaste used to brush their teeth, the resulting fluorosis is, based on recent oral health surveys 
conducted in Brazil, very mild or mild, ${ }^{41}$ and does not interfere with the quality of life of the individuals. ${ }^{42}$

3. The discussion of fluorosis risk is based on overestimated doses of fluoride ingestion, and not on the systemic effect of the fluoride ingested and absorbed. ${ }^{43,45}$

4. Low-fluoride toothpaste, in addition to not being able to prevent fluorosis, ${ }^{40}$ does not have the same anticaries effect as those containing 10001100 ppm F, either for permanent ${ }^{32}$ or deciduous teeth, ${ }^{40}$ irrespective of the formulation.

5. A general toothpaste based on $\mathrm{MFP} / \mathrm{CaCO}_{3}$ containing $1450 \mathrm{ppm}$ of total $\mathrm{F}$ is as safe as a children's toothpaste based on $\mathrm{NaF} / \mathrm{SiO}_{2}$ containing $1100 \mathrm{ppm}$ F, because the systemic effect depends on the soluble fluoride fraction (bioavailable) found in both, which is similar, and not on the total fluoride declared on the toothpaste tube..$^{45}$

\section{References}

1. Ismail AI, Bader JD. Evidence-based dentistry in clinical practice. J Am Dent Assoc. 2004 Jan;135(1):78-83.

2. McDonagh MS, Whiting PF, Wilson PM, Sutton AJ, Chestnutt I, Cooper J, et al. Systematic review of water fluoridation. BMJ. 2000 Oct 7;321(7265):855-859.

3. Marinho VCC, Higgins JPT, Logan S, Sheiham A. Fluoride toothpastes for preventing dental caries in children and adolescents. Cochrane Database Syst Rev. 2003;(1):CD002278.

4. Cury JA, Tenuta LMA, Ribeiro CC, Paes Leme AF. The importance of fluoride dentifrices to the current dental caries prevalence in Brazil. Braz Dent J. 2004;15(3):167-74.

5. Narvai PC, Frazão P, Roncalli AG, Antunes JL. Dental caries in Brazil: decline, polarization, inequality and social exclusion. Rev Panam Salud Publica. 2006 Jun;19(6):385-93. Portuguese.

6. Barbachan e Silva B, Maltz M. Prevalence of dental caries, gingivitis, and fluorosis in 12-year-old students from Porto Alegre -- RS, Brazil, 1998/1999. Pesqui Odontol Bras. 2001 JulSep;15(3):208-14. Portuguese.

7. Menezes LMB, Sousa MLR, Rodrigues LKA, Cury JA. Selfperception of fluorosis due to fluoride exposure to drinking water and dentifrice. Rev Saude Publica. 2002 Dec;36(6):752-4. Portuguese.

8. Moysés SJ, Moysés ST, Allegretti AC, Argenta M, Werneck R. Dental fluorosis: epidemiological fiction?. Rev Panam Salud Publica. 2002 Nov;12(5):339-46. Portuguese.

9. Peres KG, Latorre MR, Peres MA, Traebert J, Panizzi M. Impact of dental caries and dental fluorosis on 12-year-old schoolchil-
6. Low-F toothpastes significantly increase the risk of caries in primary teeth and do not avoid aesthetically objectionable fluorosis in permanent anterior teeth $;^{40}$ therefore, to make a public health recommendation in favor of non-fluoride or low-fluoride toothpastes, irrespective of the formulation, is socially irresponsible.

7. There is evidence that triclosan/gantrez toothpaste is effective in reducing biofilm, gingivitis, periodontitis, periimplantitis, calculus and halitosis, and that it can be recommended as a coadjuvant to mechanical biofilm control by toothbrushing.

8. There is evidence that stannous fluoride toothpaste is effective in reducing dental biofilm and gingivitis.

9. There is some evidence that arginine-based toothpaste is effective in reducing dentine hypersensitivity.

dren's self-perception of appearance and chewing. Cad Saude Publica. 2003 Jan-Feb;19(1):323-30. Portuguese.

10. Peres KG, Peres MA, Araujo CL, Menezes AM, Hallal PC. Social and dental status along the life course and oral health impacts in adolescents: a population-based birth cohort. Health Qual Life Outcomes. 2009 Nov 22;7:95.

11. Lippert F. An introduction to toothpaste - its purpose, history and ingredients. Monogr Oral Sci. 2013;23:1-14. DOI: 10.1159/000350456. Epub 2013 Jun 28.

12. Bratthall D, Hansel-Petersson G, Sundberg H. Reasons for the caries decline: what do the experts believe?. Eur J Oral Sci. 1996 Aug;104(4(Pt 2)):416-422.

13. Stookey GK. Are all fluoride dentifrices the same? In: Wei SHY, editor. Clinical uses of fluorides. Philadelphia: Lea \& Febiger; 1985. p. 105-131.

14. Bowen WH. The significance of toothpaste in oral hygiene. In: Embery G, Rolla G, editors. Clinical and biological aspects of dentifrices. New York: Oxford University Press; 1992. p. 9-12.

15. Cury JA, Tenuta LMA. Enamel remineralization: controlling the caries disease or treating the early caries lesions?. Braz Oral Res. 2009;23 Suppl 1:23-30.

16. Pearce EIF, Jenkins GN. The decomposition of monofluorophosphate by enzymes in whole human saliva. Arch Oral Biol. 1977;22(6):405-407.

17. Shellis RP, Duckworth RM. Studies on the cariostatic mechanisms of fluoride. Int Dent J. 1994 Jun;44(3 Suppl 1):263-73. 
18. Cury JA, Tabchoury CPM, Piovano S. Concentration and stability of fluoride in dentifrices market in Buenos Aires. Bol Asoc Argent Odontol Ninos. 2006 Jun-Sep;35(2):4-8. Spanish.

19. Conde NC, Rebelo MA, Cury JA. Evaluation of the fluoride stability of dentifrices sold in Manaus, AM, Brazil. Pesqui Odontol Bras. 2003 Jul-Sep;17(3):247-53.

20. Cury JA, Oliveira MJL, Martins CC, Tenuta LMA, Paiva SM. Available fluoride in toothpastes used by Brazilian children. Braz Dent J. 2010;21(5):396-400.

21. Benzian H,Holmgren C, Helderman WP. Efficacy of fluoride toothpaste over time. Braz Dent J. 2012;23(4):311-4; author reply 312-4.

22. Kay E, Locker D. A systematic review of the effectiveness of health promotion aimed at improving oral health. Community Dent Health. 1998 Sep;15(3):132-44.

23. Sheiham A. Dietary effects on dental diseases. Public Health Nutr. 2001 Apr;4(2B):569-91.

24. Eaton KA, Carlile MJ. Tooth brushing behaviour in Europe: opportunities for dental public health. Int Dent J. 2008 Oct 58;(Issue S5):287-93.

25. Santos AP, Nadanovsky P, Oliveira BH. A systematic review and meta-analysis of the effects of fluoride toothpastes on the prevention of dental caries in the primary dentition of preschool children. Community Dent Oral Epidemiol. 2012 Aug 10. DOI: 10.1111/j.1600-0528.2012.00708.x.

26. Tenuta LMA, Cury JA. Laboratory and human studies to estimate anticaries efficacy of fluoride toothpastes. Monogr Oral Sci. 2013;23:108-24.

27. Cenci MS, Tenuta LMA, Pereira-Cenci T, Del Bel Cury AA, ten Cate JM, Cury JA. Effect of microleakage and fluoride on enamel-dentine demineralization around restorations. Caries Res 2008;42(5):369-79. DOI: 10.1159/000151663.

28. Cury JA, Amaral RC, Tenuta LMA, Del Bel Cury AA, Tabchoury CPM. Low-fluoride toothpaste and deciduous enamel demineralization under biofilm accumulation and sucrose exposure. Eur J Oral Sci. 2010 Aug;118(4):370-5.

29. Tenuta LMA, Zamataro CB, Del Bel Cury AA, Tabchoury CPM, Cury JA. Mechanism of fluoride dentifrice effect on enamel demineralization. Caries Res. 2009;43(4):278-85.

30. Horowitz HS. The needs for toothpastes with lower than conventional fluoride concentrations for preschool-aged children. J Public Health Dent. 1992 Summer;52(4):216-21.

31. Ministerio de Salud. Reglamento para el uso de flúor en Odontología Preventiva. Santiago: Ministerio de Salud; 2008.

32. Walsh T, Worthington HV, Glenny AM, Appelbe P, Marinho VC, Shi X. Fluoride toothpastes of different concentrations for preventing dental caries in children and adolescents. Cochrane Database Syst Rev. 2010 Jan 20;(1):CD007868.

33. Lima TJ, Ribeiro CCC, Tenuta LMA, Cury JA. Low-fluoride dentifrice and caries lesions control in children with different caries experience: a randomized clinical trial. Caries Res 2008;42(1):46-50.
34. Kusano SC, Tenuta LMA, Del Bel Cury AA, Cury JA. Timing of fluoride toothpaste use and enamel-dentin demineralization. Braz Oral Res. 2011 Sep-Oct;25(5):383-7.

35. Heijnsbroek M, Paraskevas S, Van der Weijden GA. Fluoride interventions for root caries: a review. Oral Health Prev Dent. 2007;5(2):145-52.

36. Pine CM, McGoldrick PM, Burnside G, Curnow MM, Chesters RK, Nicholson J, et al.. An intervention programme to establish regular toothbrushing: understanding parents' beliefs and motivating children. Int Dent J. 2000;Suppl Creating A Successful:312-23.

37. Paes Leme AF, Dalcico R, Tabchoury CPM, Del Bel Cury AA, Rosalen PL, Cury JA. In situ effect of frequent sucrose exposure on enamel demineralization and on plaque composition after APF application and F dentifrice use. J Dent Res. 2004 Jan;83(1):71-5.

38. Marinho VC, Higgins JP, Sheiham A, Logan S. One topical fluoride (toothpastes, or mouthrinses, or gels, or varnishes) versus another for preventing dental caries in children and adolescents. Cochrane Database Syst Rev. 2004;(1):CD002780. Review.

39. Wong MC, Glenny AM, Tsang BW, Lo EC, Worthington HV, Marinho VC. Topical fluoride as a cause of dental fluorosis in children. Cochrane Database Syst Rev. 2010 Jan 20;(1):CD007693.

40. Santos AP, Oliveira BH, Nadanovsky P. Effects of low and standard fluoride toothpastes on caries and fluorosis: systematic review and meta-analysis. Caries Res. 2013 Apr 6;47(5):382-90.

41. Brasil. Ministério da Saúde. Secretaria de Atenção à Saúde, Departamento de Atenção Básica, Coordenação Nacional de Saúde. SB Brasil 2010. Pesquisa nacional de saúde bucal. Principais resultados. Brasília (DF): Ministério da Saúde; 2011.

42. Chankanka O, Levy SM, Warren JJ, Chalmers JM. A literature review of aesthetic perceptions of dental fluorosis and relationships with psychosocial aspects/oral health-related quality of life. Community Dent Oral Epidemiol. 2010 Apr;38(2):97-109.

43. Martins CC, Paiva SM, Lima-Arsati YB, Ramos-Jorge ML, Cury JA. Prospective study of the association between fluoride intake and dental fluorosis in permanent teeth. Caries Res. 2008;42(2):125-33.

44. Warren JJ, Levy SM, Broffitt B, Cavanaugh JE, Kanellis MJ, Weber-Gasparoni K. Considerations on optimal fluoride intake using dental fluorosis and dental caries outcomes - a longitudinal study. J Public Health Dent. 2009 Spring;69(2);111-5.

45. Falcão A, Tenuta LMA, Cury JA. Fluoride gastrointestinal absorption from $\mathrm{Na} 2 \mathrm{FPO} 3 / \mathrm{CaCO}_{3}$ and $\mathrm{NaF} / \mathrm{SiO}_{2}$-based toothpastes. Caries Res. 2013;47(3):226-33.

46. Oliveira MJ, Martins CC, Paiva SM, Tenuta LMA, Cury JA. Estimated fluoride doses from toothpastes should be based on total soluble fluoride. Int J Environ Res Public Health. 2013 Nov 1;10(11):5726-36.

47. Cury JA, Del Fiol FS, Tenuta LMA, Rosalen PL. Low-fluoride dentifrice and gastrointestinal fluoride absorption after meals. J Dent Res. 2005 Dec;84(12):1133-7. 
48. Ellwood RP, Cury JA. How much toothpaste should a child under the age of 6 years use?. Eur Arch Paediatr Dent. 2009 Sep;10(3):168-74.

49. Rösing CK, Tenuta LMA, Cury JA. Dentifrícios: muito além de anticárie. Clin Int J Braz Dent. 2011 Jan-Mar;(7)1:16-9.

50. Ciancio SG. Controlling biofilm with evidence-based dentifrices. Compend Contin Educ Dent. 2011 Jan-Feb;32(1):70-6.

51. Trombelli L, Farina R. Efficacy of triclosan-based toothpastes in the prevention and treatment of plaque-induced periodontal and peri-implant diseases. Minerva Stomatol. 2013 Mar;62(3):7188.
52. Niederman R. Stannous fluoride toothpastes reduce the gingival index more than sodium fluoride toothpastes. Evid Based Dent. 2007;8(3):74-5.

53. Poulsen S, Errboe M, Lescay Mevil Y, Glenny AM. Potassium containing toothpastes for dentine hypersensitivity. Cochrane Database Syst Rev. 2006 Jul 19;(3):CD001476.

54. Sharif MO, Iram S, Brunton PA. Effectiveness of argininecontaining toothpastes in treating dentine hypersensitivity: a systematic review. J Dent. 2013 Jun;41(6):483-92.

55. Davies R, Scully C, Preston AJ. Dentifrices - an update. Med Oral Patol Oral Cir Bucal. 2010 Nov 1;15(6):e976-82. 